\title{
Deferoxamine Hydrochloride
}

National Cancer Institute

\section{Source}

National Cancer Institute. Deferoxamine Hydrochloride. NCI Thesaurus. Code C1972.

The hydrochloride salt form of deferoxamine, an iron chelating agent. Deferoxamine chelates iron from intra-lysosomal ferritin and hemosiderin forming ferrioxamine, a water-soluble chelate excreted by the kidneys and in the feces via the bile. This agent does not readily bind iron from transferrin, hemoglobin, myog lobin or cytochrome. $(\mathrm{NCl})$ 